\title{
The role of affordances in inhibition of return
}

\author{
LUCIA RIGGIO, ILARIA PATTERI, ANNALISA OPPO, and GIOVANNI BUCCINO \\ Università di Parma, Parma, Italy
}

and

CARLO UMILTÀ
Università di Padova, Padova, Italy

\begin{abstract}
Inhibition of return (IOR) is a response delay that occurs when the target is preceded by an irrelevant stimulus (cue) at the same location. IOR can be object based, as well as location based. The aim of the present study was to investigate the role of the pragmatic features of a visually presented object in causing IOR. Two experiments were carried out using different objects as stimuli, for which the graspable part (affordance) was clearly defined. The presentation of a whole object, with the part commonly used to grasp it located below, served as a cue. The presentation of either the graspable or the ungraspable part of the cued or uncued object served as the target. Results showed that responses were slower when the graspable part was shown in the cued location than when the ungraspable part was shown in the same location. The effect was apparently linked to the kind of action necessary to grasp an object.
\end{abstract}

Inhibition of return (IOR) is characterized by a delay in responding to a target shown in a location that had been previously stimulated. In the paradigmatic situation (e.g., Posner \& Cohen, 1984), while participants fixate a central point, two successive stimuli (cue and target) are presented with equal probability in the same peripheral location or in symmetrical locations in the two opposite visual fields. The participants have to ignore the cue and respond to the target. The typical result is that responses are slower when the cue and the target are shown in the same location than when they are presented in two different locations. Location-based IOR is a quite robust phenomenon, repeatedly shown, and is considered to be linked to midbrain neural substrates (i.e., the superior colliculus) and oculomotor programming (e.g., Klein \& Taylor, 1994; Rafal, Calabresi, Brennam, \& Sciolto, 1989; Sapir, Soroker, Berger, \& Henik, 1999). The function of location-based IOR should be that of permitting an efficient visual search by favoring orienting toward novel locations (Klein, 1988, 2000). In other words, IOR results from the withdrawal of attention from a previously attended spatial location and to attention's being inhibited from returning to that spatial location. The frame of reference in which that happens is linked to the type of space representation in which at-

The authors thank L. Fogassi and G. Rizzolatti for helpful suggestions during the study and B. M. Sheliga for preparing the software and providing useful comments on this research. We also thank Anne P. Hillstrom and two anonymous reviewers for suggestions that were very helpful in improving an earlier version of the manuscript. Correspondence concerning this article should be addressed to $L$. Riggio, Dipartimento di Neuroscienze, Università di Parma, Via Volturno 39, 43100 Parma, Italy (e-mail: riggio@unipr.it). tention operates. Recently, Briand, Larrison, and Sereno (2000; see also Maylor, 1985) showed that the rate of development of IOR is different for saccadic and manual responses. According to these authors, this result is difficult to explain if it is supposed that the frame of reference of IOR (and spatial attention) is a multipurpose representation of visual space, separated from sensorimotor circuits, whereas it can fit with the premotor theory of attention (Rizzolatti, Riggio, Dascola, \& Umiltà, 1987; Rizzolatti, Riggio, \& Sheliga, 1994), which proposes that spatial attention derives from the activation of different pragmatic maps that transform visual information into different types of actions, in which the attentional consequences can be different.

Other types of IOR have been described and attributed to object representations (e.g., Abrams \& Dobkin, 1994; Gibson \& Egeth, 1994; Tipper, Driver, \& Weaver, 1991; Tipper, Jordan, \& Weaver, 1999). If IOR is strictly related to transformations of visual input into action, one might predict the occurrence of a type of IOR due to pragmatic features (affordances) of visually presented objects. Objects are made of different parts with different pragmatic roles. For instance, in a knife, we can distinguish between blade and handle, but only the handle is used for grasping the object. In order to grasp an object, individuals have not only to code its location, but also to code its pragmatic features and to transform them into the most appropriate action for acting on this object.

It is well known that this visuomotor transformation from object pragmatic features to action relies on a neural circuit consisting of area AIP and area F5 in the monkey (see Rizzolatti \& Luppino, 2001, for a review) and of the ventral premotor cortex and an area adjacent to the intraparietal sulcus in humans (Binkofski et al., 1999). The 
appearance of an object facilitates motor responses associated with it, as has been testified to by behavioral studies (e.g., Craighero, Fadiga, Rizzolatti, \& Umiltà, 1998; Tucker \& Ellis, 1998), possibly for an automatic recruitment of the frontoparietal circuit, as has been shown by neurophysiological (e.g., Murata et al., 1997) and brainimaging (e.g., Chao \& Martin, 2000; Grezes, Tucker, Armony, Ellis, \& Passingham, 2003) studies.

Given the experimental evidence that there are automatic visuomotor transformations in response to pragmatic features of objects, we hypothesized that after the presentation of a graspable object as a cue, one may see greater IOR to the presentation of the grasping part than of the nongraspable part of it. In other words, we expected not only both location-based IOR and object-based IOR, but also a prominent role of the pragmatic features of an object in causing IOR. Therefore, we carried out two experiments in which we used, as stimuli, objects in which the distinction between the graspable and the ungraspable parts was clearly defined. In Experiment 1, the stimuli were drawings of sharp objects; in Experiment 2, we presented pictures of nonsharp objects, to extend the results in a more ecological fashion.

\section{EXPERIMENT 1}

\section{Method}

Participants. Twelve undergraduate students, 3 men and 9 women, 19-29 years of age, participated in this experiment. They were all right-handed and had normal or corrected-to-normal vision. All of them were naive as to the purpose of the experiment.

Apparatus and Procedure. The stimuli were displayed on a VGA monitor of an IBM-compatible PC, which generated and recorded the responses. The participants sat in front of the monitor at a distance of about $57 \mathrm{~cm}$ from the screen. Eye height was adjusted to the level of the fixation point. Responses were executed by pressing, with the right index finger, a key placed in front of the subject on the meridian saggital axis. Eye movements were monitored using an electrooculogram.

The stimuli were images of two upright objects (knife and scissors), presented on a black background. The cue consisted of the presentation of the whole image of one of the two objects, whereas the target consisted of the presentation of the graspable or ungraspable part of the cued or the uncued object. All the stimuli, including both whole-object cues and individual-part targets, were shown in the periphery (centered at $5^{\circ}$ ) and were centered on the horizontal meridian. Each trial began with presentation of a fixation cross $\left(0.4^{\circ} \times 0.4^{\circ}\right)$ at the geometrical center of the screen. It remained on view up to the end of the trial. After a 500-msec delay, the cue was presented at $5^{\circ}$ to the left or the right of the fixation cross (center to

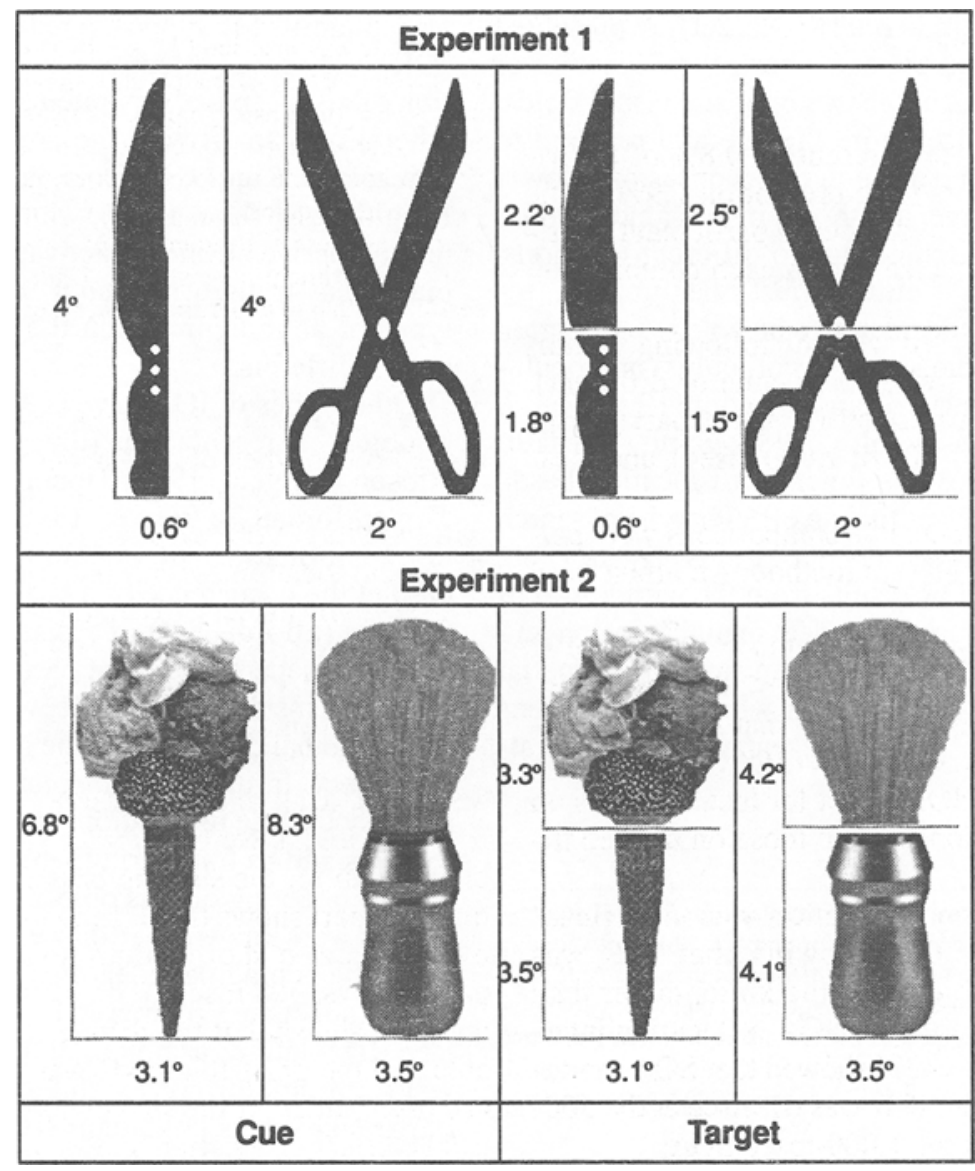

Figure 1. Stimuli (cues and targets) used in Experiments 1 and 2. 
center). The knife was inscribed in a $0.6^{\circ} \times 4^{\circ}$ matrix, the scissors in a $2^{\circ} \times 4^{\circ}$ matrix. For the knife, the height of the ungraspable part (blade) was $2.2^{\circ}$ and that of the graspable part (handle) was $1.8^{\circ}$. For the scissors, the ungraspable part (blades) measured $2.5^{\circ}$ in height, and the graspable part $1.5^{\circ}$ (see Figure 1). The cue disappeared after $200 \mathrm{msec}$ and was followed, after an interval of 500 or $1,000 \mathrm{msec}$ from its onset (stimulus onset asynchrony [SOA]), by the target (ungraspable or graspable part of the same or the different object) in the same or in the opposite location. The target was displayed for 200 msec. The cue and target could be presented in the same location (cued trials) or in the opposite-field location (uncued trials). The identity and location of the cue were unrelated to the identity and location of the target. The participants were fully informed of that. They were instructed to fixate the central cross, to ignore the cue, and to press, as quickly as possible, the response key to the onset of the target, regardless of its identity and location (simple reaction time [RT]). The response ended the trial and was followed by a visual feedback about speed and accuracy. RT was measured to the nearest millisecond, from target onset to response execution. On about $10 \%$ of the trials (catch trials), the target was not presented, and the participants were required to refrain from responding. RTs shorter than $130 \mathrm{msec}$ or longer than $1,000 \mathrm{msec}$ were considered errors, as were trials in which eye movement was detected or when a response occurred on catch trials. These trials were discarded and subsequently rerun.

Overall, the experiment consisted of 720 correct trials--that is, trials in which no error occurred (640 experimental trials plus 80 catch trials). They were run in a single session. The design of the experiment was within subjects and provided 20 trials for each combination of the following variables: identity of the cue and target, part of the tool, SOA, and location.

\section{Results}

Eye movement errors were present on $0.8 \%$ of the trials; all other types of errors were present on $1.9 \%$ of the trials. Medians were computed for each participant on trials on which no error occurred and in each combination of the variables tested.

An ANOVA was performed with the following withinsubjects variables: cue/target object (same or different), identity of the target (knife or scissors), target part (graspable or ungraspable), SOA (500 or 1,000 msec), and location (cued or uncued).

Whenever appropriate, post hoc comparisons were performed with the Newman-Keuls method. An alpha level of .05 was always used.

The main effects of identity $[F(1,11)=135.51, p<$ $.001]$ and location $[F(1,11)=49.47, p<.001]$ were significant. The effect of identity showed that RTs were longer for the knife than for the scissors ( $268 \mathrm{vs} .258 \mathrm{msec}$ ). Also, there was a reliable IOR effect for location: RTs on cued trials were $54 \mathrm{msec}$ longer than those on uncued trials ( 290 vs. $236 \mathrm{msec}$ ).

The identity $\times$ location interaction was significant $[F(1,11)=15.50, p<.003]$, showing that IOR was greater when the target object was the knife, rather than the scissors $(62$ vs. $46 \mathrm{msec})$. The SOA $\times$ location interaction $[F(1,11)=6.96, p<.03]$ showed that SOA modulated the magnitude of IOR: IOR was $61 \mathrm{msec}$ at the 500$\mathrm{msec}$ SOA and $47 \mathrm{msec}$ at the $1,000-\mathrm{msec}$ SOA.

Both the part $\times$ location $[F(1,11)=5.43, p<.04]$ and the object $\times$ part $\times$ location $[F(1,11)=16.84, p<$ $.002]$ interactions were significant. When the target was presented in the cued location, RTs were $6 \mathrm{msec}$ longer for the graspable than for the ungraspable part (293 vs. $287 \mathrm{msec} ; p<.02$ ), whereas RTs were nearly identical in the uncued location ( $236 \mathrm{vs}$. $237 \mathrm{msec}$ for the graspable and the ungraspable parts, respectively). However, the object $\times$ part $\times$ location interaction shows that on cued trials, when the target was different from the cued object, it was irrelevant whether the ungraspable or the graspable part was presented ( $288 \mathrm{msec}$ in either case). In contrast, when the same object was used as the cue and the target, RTs were longer (an 11-msec difference) when the graspable part was shown than when the ungraspable part was shown ( 298 vs. $287 \mathrm{msec})$. There was no significant difference between RTs on the uncued trials. Figure 2 shows the relevant data for the three-way interaction.

\section{EXPERIMENT 2}

\section{Method}

Participants. Sixteen undergraduate students, 3 men and 13 women, 19-27 years of age, who had not participated in the previous experiment, volunteered to take part in this experiment. They were selected as before.

Apparatus and Procedure. The apparatus and procedure were identical to those used in Experiment 1, except that nonsharp graspable objects were used. The stimuli consisted of pictures of real objects, an ice-cream cone and a shaving brush (see Figure 1). The ice cream was inscribed in a $3.1^{\circ} \times 6.8^{\circ}$ (ungraspable part, $3.3^{\circ}$; graspable part, $3.5^{\circ}$ ) matrix; the shaving brush was inscribed in a $3.5^{\circ} \times 8.3^{\circ}$ (ungraspable part, $4.2^{\circ}$; graspable part, $4.1^{\circ}$ ) matrix. As before, the participants were required to maintain their eyes at fixation, to ignore the cue (whole object) as irrelevant for the task, and to respond, as quickly as possible, to the onset of the target (object part), regardless of its identity and location.

The experiment consisted of 720 correct trials, run in a single session, with 640 experimental trials and 80 catch trials.

\section{Results}

Eye movement errors were present on $0.5 \%$ of the trials; all other types of errors were present on $3.3 \%$ of the trials. As in Experiment 1, an ANOVA was performed with cue/target object, identity of the target, target part, $\mathrm{SOA}$, and location as within-subjects factors.

The main effects of identity $[F(1,15)=8.57, p<$ $.02]$, location $[F(1,15)=199.60, p<.001]$, and part $[F(1,15)=7.32, p<.02]$ were significant. The following interactions were also significant: identity $\times$ part $[F(1,15)=10.76, p<.006]$, location $\times$ part $[F(1,15)=$ $8.94, p<.01]$, and location $\times \operatorname{SOA}[F(1,15)=29.56$, $p<.001]$. RTs were, overall, $4 \mathrm{msec}$ shorter for the ice cream than for the shaving brush ( $303 \mathrm{vs.} 307 \mathrm{msec}$ ); the effect of part shows that RTs to the ungraspable part were overall $6 \mathrm{msec}$ shorter than responses to the graspable part ( 302 vs. $308 \mathrm{msec})$. The interaction between identity and part shows that the difference between the ungraspable and the graspable parts was larger for the ice cream $(12 \mathrm{msec})$ than for the shaving brush $(2 \mathrm{msec})$.

The effect of location shows an IOR effect of $57 \mathrm{msec}$ (334 vs. $277 \mathrm{msec}$ for cued and uncued trials, respectively). As in Experiment 1, SOA modulated the magnitude of IOR with an effect of $66 \mathrm{msec}$ ( $338 \mathrm{vs} .272 \mathrm{msec}$ ) 


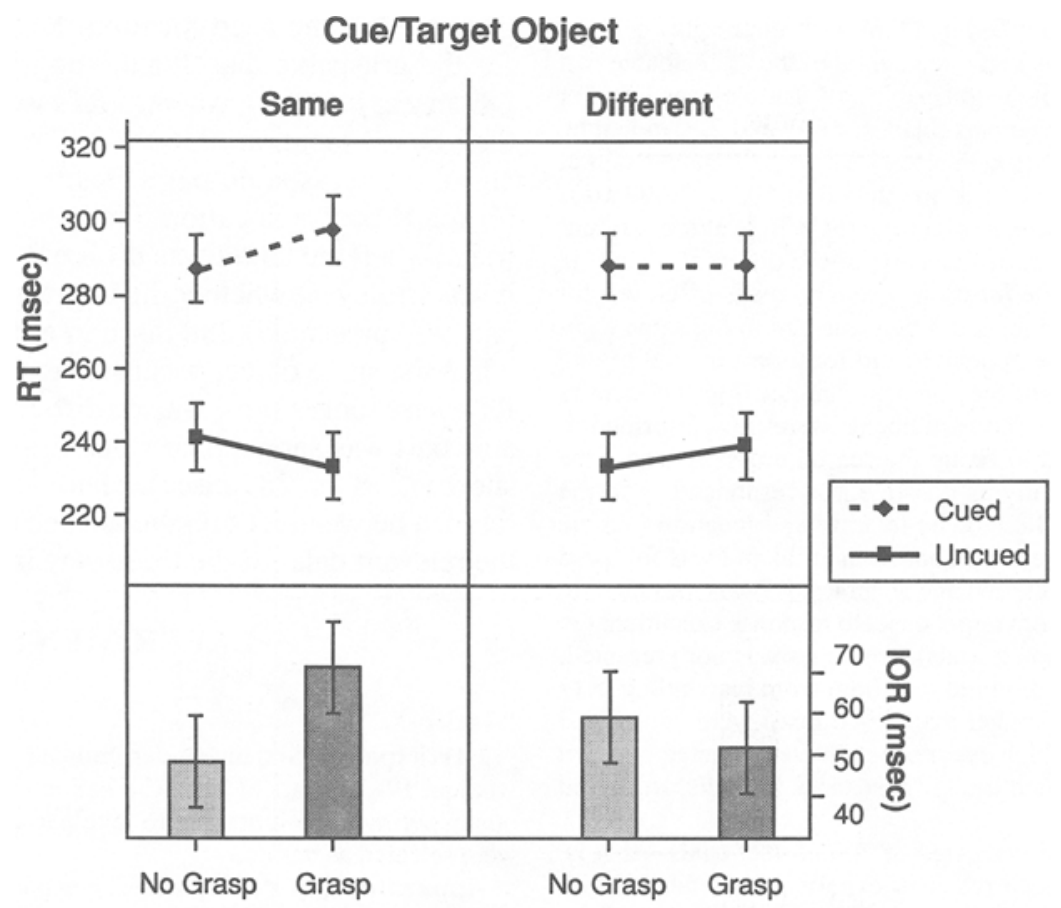

Target Part

Figure 2. Mean reaction times (RTs, in milliseconds) for cued and uncued trials related to the cue/target object and target part variables in Experiment 1. Inhibition of return (IOR) values are also reported. Bars refer to standard errors.

and $47 \mathrm{msec}$ ( 329 vs. $282 \mathrm{msec}$ ) at 500- and 1,000-msec SOAs, respectively. More important, the interaction between location and part showed that when the target was presented in the cued location, RTs to the graspable part were $10 \mathrm{msec}$ longer (significantly) than RTs to the ungraspable part ( 339 vs. $329 \mathrm{msec}$ ), whereas the difference was not significant in the uncued location ( 278 vs. $276 \mathrm{msec}$ for the graspable and the ungraspable parts, respectively). However, contrary to the results of the previous experiment, the object $\times$ part $\times$ location interaction was not significant $(p>.80$; see Figure 3$)$.

\section{DISCUSSION}

There is general agreement that IOR is related to our capacity to orient toward novel locations and objects. It is also well known that visual presentation of an object automatically triggers the motor actions most convenient for acting on it (Tucker \& Ellis, 1998). We tested, through an IOR paradigm, the role of the pragmatic features of a visually presented object in causing IOR. The results of the present study clearly support the notion that the pragmatic features of objects modulate IOR. In Experiment 1, with sharp objects, IOR was greater when the target was the graspable part of the cue than when the target was the ungraspable part of it. For example, IOR was greater when the target was the handle of the knife, rather than its blade. This effect was evident only when the target was presented in the cued location, in keeping with a location-related
IOR. In Experiment 2, with different nonsharp objects, responses were again slower when the graspable, rather than the ungraspable, target part was shown in the cued location. However, this time the effect was not confined to the cued object. Therefore, if the cue was, for example, the picture of the ice cream, IOR was greater not only when the target was the graspable part of it, but also when the target was the graspable part of the other object (shaving brush) used in this experiment. The most plausible explanation of the results from both experiments is that the effect can be attributed to the way in which the objects are grasped. In fact, the action required to act on the handle of a knife is completely different from the action required to grasp scissors. Therefore, because the pragmatic features of the knife and the scissors recruited different actions in order to act on them, in Experiment 1 affordance-related IOR was present only when the cue and the target referred to the same object - or in other words, when the same action was recruited. In Experiment 2, although the objects were different, the graspable parts of them involved a very similar grasping action for acting on them. In keeping with this, the results showed that whatever the cued object, the graspable parts were equally efficient in causing the effect. Taken together, these results not only show that IOR is modulated by the pragmatic features of an object (graspable vs. ungraspable part), but also strongly suggest that this effect is grasp specific--that is, specific for the most appropriate action necessary to grasp a specific object. Also in keeping with the present behavioral 


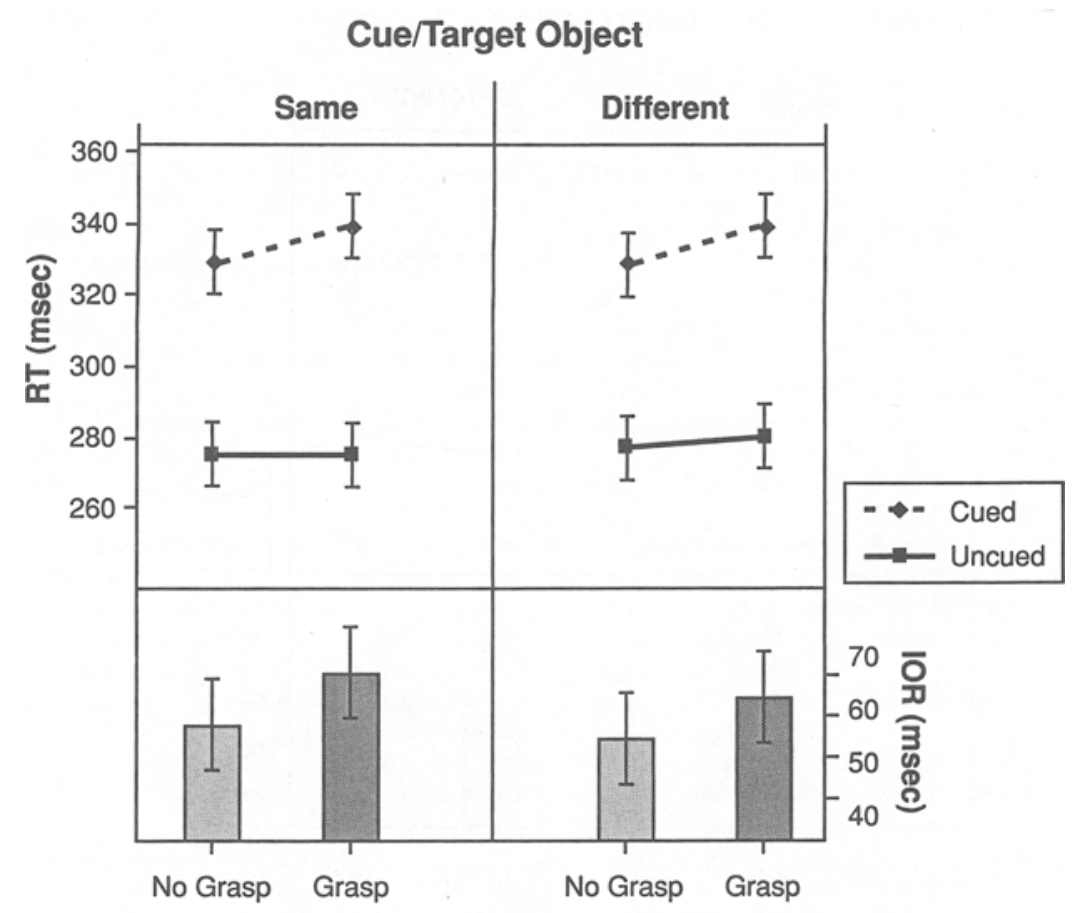

Target Part

Figure 3. Mean reaction times (RTs, in milliseconds) for cued and uncued trials related to the cue/target object and target part variables in Experiment 2 . Inhibition of return (IOR) values are also reported. Bars refer to standard errors.

results are the findings of single-neuron studies showing that in the AIP-F5 circuit, there are neurons coding for specific grasping actions: precision grip for small objects and whole hand and finger prehension for large objects (Murata et al., 1997; Murata, Gallese, Luppino, Kaseda, \& Sakata, 2000; Rizzolatti et al., 1988).

There is, however, an alternative, although not mutually exclusive, explanation for the present results. Vecera, Behrmann, and McGoldrick (2000) have shown that part-based attention occurs at the same time as objects are processed. It may be that different parts of an object have a different salience for object recognition. Indeed, theories of object recognition argue that part segmentation is required to recognize an object (e.g., Biederman, 1987; Marr, 1982). So, the handle of a knife may capture attention more easily than the blade because it is more salient. In this view, the greater inhibition for the handle found in the present study would be a consequence of an asymmetrical distribution of spatial attention between the two parts of the knife. However, an explanation based merely on the distribution of spatial attention, regardless of the pragmatic role of the part, is not sufficient to explain the present findings. In fact, the different parts were always presented centered on the horizontal meridian, thus occupying roughly the same location. Therefore, it must be concluded that the pragmatic role of the part, and not the distribution of spatial attention, caused the effect.

The effect, however, was also linked to the locus of presentation of the cue (location-based IOR). Thus, the role of the part alone cannot explain the results either. In contrast, the importance of the locus of presentation of the object is easily explained in terms of affordances, because the inhibition is related to the specific action of grasping an object in a specific location. In this respect, neurophysiological studies clearly have shown that the code of pragmatic features of an object carried out in the ventral premotor cortex and in the inferioparietal lobule is parallel to that of its spatial location carried out in different, distinct parts of the same brain regions (Fogassi et al., 1996; Graziano, $\mathrm{Hu}, \&$ Gross, 1997).

In conclusion, the present experiments show that IOR is modulated by the pragmatic features of objects, thus suggesting that the neural substrates responsible for sensorimotor transformations required to act properly on an object may activate the inhibitory processes leading to IOR. Further studies should clarify how selective this modulation is in relation to the specific grasping actions (precision grip or whole hand and finger prehension) required to interact with objects.

\section{REFERENCES}

ABRAMS, R. A., \& DOBKIN, R. S. (1994). Inhibition of return: Effects of attentional cuing on eye movement latencies. Journal of Experimental Psychology: Human Perception \& Performance, 20, 467-477.

BiEDeRMAN, I. (1987). Recognition-by-components: A theory of human image understanding. Psychological Review, 94, 115-147.

Binkofski, F., Buccino, G., Posse, S., Seitz, R. J., Rizzolatti, G., \& FREUND, H. (1999). A fronto-parietal circuit for object manipulation 
in man: Evidence from an fMRI-study. European Journal of Neuroscience, 11, 3276-3286.

Briand, K. A., Larruson, A. L., \& Sereno, A. B. (2000). Inhibition of return in manual and saccadic response systems. Perception \& Psychophysics, 62, 1512-1524.

CHAO, L. L., \& MARTIN, A. (2000). Representation of manipulable manmade objects in the dorsal stream. NeuroImage, 12, 478-484.

Craighero, L., Fadiga, L., Rizzolatti, G., \& Umiltà, C. (1998). Visuomotor priming. Visual Cognition, 5, 109-125.

Fogassi, L., Gallese, V., Fadiga, L., Luppino, G., Matelli, M., \& RizzolatTI, G. (1996). Coding of peripersonal space in inferior premotor cortex (area F4). Journal of Neurophysiology, 76, 141-157.

GIBSON, B. S., \& EGETH, H. (1994). Inhibition of return to object-based and environment-based locations. Perception \& Psychophysics, 55, 323-339.

Graziano, M. S., Hu, X. T., \& Gross, C. G. (1997). Coding the locations of objects in the dark. Science, 277, 239-241.

Grezes, J., Tucker, M., Armony, J., Ellis, R., \& Passingham, R. E. (2003). Objects automatically potentiate action: An fMRI study of implicit processing. European Journal of Neuroscience, 17, 2735-2740.

KLEIN, R. M. (1988). Inhibitory tagging system facilitates visual search. Nature, 334, 430-431.

KLEIN, R. M. (2000). Inhibition of return. Trends in Cognitive Sciences, 4, 138-147.

KLEIN, R. M., \& TAYLOR, T. L. (1994). Categories of cognitive inhibition with reference to attention. In D. Dagenbach \& T. H. Carr (Eds.), Inhibitory mechanisms in attention, memory, and language (pp. 113150). San Diego: Academic Press.

MARR, D. (1982). Vision: A computational investigation into the human representation and processing of visual information. San Francisco: Freeman.

MAYLOR, E. A. (1985). Facilitatory and inhibitory components of orienting in visual space. In M. I. Posner \& O. S. M. Marin (Eds.), Attention and performance $X I$ (pp. 189-204). Hillsdale, NJ: Erlbaum.

Murata, A., Fadiga, L., Fogassi, L., Gallese, V., Raos, V., \& RizzolatTi, G. (1997). Object representation in the ventral premotor cortex (area F5) of the monkey. Journal of Neurophysiology, 78, 2226-2230.

Murata, A., Gallese, V., Luppino, G., Kaseda, M., \& Sakata, H. (2000). Selectivity for the shape, size, and orientation of objects for grasping in neurons of monkey parietal area AIP. Journal of Neurophysiology, 83, 2580-2601.
POSNER, M. I., \& COHEN, Y. (1984). Components of visual orienting. In H. Bouma \& D. G. Bouwhuis (Eds.), Attention and performance $X$. Control of language processes (pp. 531-556). Hillsdale, NJ: Erlbaum.

Rafal, R. D., Calabresi, P. A., Brennam, C. W., \& Sciolto, T. K (1989). Saccade preparation inhibits reorienting to recently attended locations. Journal of Experimental Psychology: Human Perception \& Performance, 15, 673-685.

Rizzolatti, G., Camarda, R., Fogassi, L., Gentilucci, M., LuPPino, G., \& MATELLI, M. (1988). Functional organization of inferior area 6 in the macaque monkey: II. Area F5 and the control of distal movements. Experimental Brain Research, 71, 491-507.

RizzolatTI, G., \& LuPPINO, G. (2001). The cortical motor system. Neuron, 31, 889-901.

Rizzolatti, G., Riggio, L., Dascola, I., \& Umiltà, C. (1987). Reorienting attention across the horizontal and vertical meridians: Evidence in favor of a premotor theory of attention. Neuropsychologia, $25,31-40$.

Rizzolatti, G., Riggio, L., \& Sheliga, B. M. (1994). Space and selective attention. In C. Umiltà \& M. Moscovitch (Eds.), Attention and performance $X V$ : Conscious and nonconscious information processing (pp. 231-265). Cambridge, MA: MIT Press.

SAPIR, A., SOROKER, N., BERGER, A., \& HENIK, A. (1999). Inhibition of return in spatial attention: Direct evidence for collicular generation. Nature Neuroscience, 2, 1053-1054.

TiPPER, S. P., DrIVER, J., \& WeAVER, B. (1991). Object-centered inhibition of return of visual attention. Quarterly Journal of Experimental Psychology, 43A, 289-298.

TIPPER, S. P., Jordan, H., \& WEAVEr, B. (1999). Scene-based and object-centered inhibition of return: Evidence for dual orienting mechanisms. Perception \& Psychophysics, 61, 50-60.

TUCKER, M., \& Ellis, R. (1998). On the relations between seen objects and components of potential actions. Journal of Experimental Psychology: Human Perception \& Performance, 24, 830-846.

Vecera, S. P., BehrmanN, M., \& McGoldrick, J. (2000). Selective attention to the parts of an object. Psychonomic Bulletin \& Review, 7, 301-308.

(Manuscript received October 28, 2005; revision accepted for publication April 21, 2006.) 